\title{
A Study to Assess the Effectiveness of Structured Teaching Program on Knowledge Regarding Alcohol Use and Its Harmful Effects Among High School Children at Municipal Corporation School in Tirupati
}

\author{
R Snehalatha*, \\ M Bhagyalakshmi and \\ S Hemalatha \\ Sri Venkateswara Institute of Medical \\ Sciences (SVIMS), Tirupati, Chittor (Dist), \\ Andhra Pradesh, India
}

\section{*Corresponding author: R Snehalathada \\ झ snehalatha9997@gmail.com}

Aim: "To assess the effectiveness of structured teaching program on knowledge regarding alcohol use and its harmful effects among high school children at Municipal Corporation School in Tirupati".

Materials and methods: A quasi-experimental research with one group pretest posttest design was used and the study was conducted in Municipal Corporation School in Tirupati, Andhra Pradesh. The population consists of high school children. The sample size was 60 high school children, who fulfilled the inclusion criteria. The tool used for data collection was structured questionnaire.

Results: The study findings revealed that among 60 high school children 15 (25\%) had inadequate knowledge, 24 (40\%) had moderate knowledge and 21 (35\%) had adequate knowledge in pretest after administration of structured teaching program, the posttest findings revealed that $8(13.3 \%)$ had inadequate knowledge $28(46.7 \%)$ had moderate knowledge and $24(40 \%)$ had adequate knowledge. That the pretest means value and standard deviation scores was $15.40+2.499$ and the posttest means value and standard deviation was $24.08+2.499$ and the calculated $t$-value was 15.846 . Which was statistically significant at $p=0.01$. The above results revealed that there was a significant difference between pre-test and post-test scores among scores among high school children after structured teaching program.

Conclusion: The high school children had gained knowledge on Alcohol use and its harmful effects after the structured teaching program in the post test assessment.

Received: August 14, 2017; Accepted: September 18, 2017; Published: September 26, 2017

\section{Introduction}

Alcohol is a drug and classified as sedative, tranquilizer, depending upon the quantity consumed. Alcohol is self-induced intoxication and socially acceptable [1].

Alcohol use is worldwide social and medical problem over the past 30-40 years. Alcohol consumption has increased in quantity and frequency. The age at which people start drinking has also declined. The population group at great risk is those undergoing rapid socioeconomic and cultural changes; they view alcohol as a symbol of prestige and social status [2]. According to the National Survey on Drug Use and Health (NSDUH) is estimated $6,23,000$ adolescent ages $12-17$ years (2.5 percent of this age group) suffering with alcohol use disorders in 2015.This number includes 2,98,000 males (2.3\% of males in this age group) and $3,25,000$ females ( $2.7 \%$ of females in this age group) suffering with alcohol use disorders [3] .

In 2014 World Health Organization (WHO) released "Global status report" on alcohol and health and reported that alcohol contributed to more than 200 diseases and injuries related to health conditions. 


\section{Materials and Methods}

\section{Descriptive statistics}

Mean, Standard deviation and Frequency percentage distribution.

\section{Inferential statistics}

i. Chi square

ii. Paired t-test

iii. Kuder and Richardson formula was used for reliability

These statistical methods are used in this study

\section{Research approach}

The quasi experimental approach.

\section{Research design}

One group pre-test-post-test design.

\section{Variables}

Independent variables: Structured teaching program on alcohol use and its harmful effects among high school children facilitated by poster presentation and flash cards and slides.

Dependent variables: Knowledge of high School children on alcohol use and its harmful effects.

Demographic variable: Age, education, occupation, residence, type of family, living area, habit of alcohol in family and friends.

\section{Setting of the study}

Municipal Corporation School in Tirupati.

\section{Population}

Boys and girls of $8^{\text {th }}$ to $10^{\text {th }}$ class students.

\section{Sample}

High school children, who were falling under inclusion criteria.

\section{Sample size}

60 high school children at Municipal Corporation School in Tirupati.

\section{Sampling technique}

Non probability sampling technique.

\section{Criteria for sample selection}

Inclusion criteria: Students who were willing to participate in the study. Students, who can read, write and understand English or Telugu, high school children of age between $13-15$ years. studying at Municipal Corporation School in Tirupati.

Exclusion criteria: Students who were not available during the conduction of the study and who were not willing to participate?

\section{Development and Description of the tool}

Section I: Socio demographic data: Age, education, occupation, residence, type of family, residence, living area, habit of alcohol in family and friends.

Section II: Structured knowledge questionnaire regarding alcohol use and its harmful effects: Each correct answer carries a score of " 1 " mark. The wrong answer carries " 0 " mark . Thus a total score of " 30 " allotted under knowledge regarding alcohol use and its harmful effects.

\section{Score interpretation:}

- $\quad$ Adequate knowledge $>75 \%$ (21-30)

- Moderate knowledge 51-75\% (11-20)

- Inadequate knowledge $<50 \%(1-10)$

\section{Structured teaching materials}

The method of teaching was lecture cum discussion. Poster presentation and flash cards, slides were prepared to facilitate teaching.

\section{Description of the STP}

The STP is titled as "Alcohol use and its harmful effects" consists of introduction, definition, incidence, etiology, effects, complications and levels of prevention.

\section{Procedure for data collection}

Permission was obtained from the, Headmistress of Municipal Corporation School in Tirupati. By using non probability purposive sampling technique 60 high school children were selected as the sample and data was obtained for a period of 3 weeks.

Student's knowledge levels are assessed by using structured questionnaire. After that structured teaching programs on alcohol use and its harmful effects was given for 45 minutes and doubts were clarified. After 7 days post-test was conducted to assess their knowledge levels by using the same questions.

\section{Results}

The study findings revealed that among 60 high school children 15 (25\%) had inadequate knowledge, 24 (40\%) had moderate knowledge and 21 (35\%) had adequate knowledge in pretest after administration of structured teaching program, the posttest findings revealed that $8(13.3 \%)$ had inadequate knowledge 28 (46.7\%) had moderate knowledge and 24 (40\%) had adequate knowledge. That the pretest means value and standard deviation scores was $15.40+2.499$ and the posttest mean value and standard deviation was $24.08+2.499$ and the calculated t-value was 15.846 . Which was statistically significant at $p=0.01$. The above results revealed that there was a significant difference between pre- test and post test scores among scores among high school children after structured teaching program. 


\section{Discussion}

The first objective of the study was to assess the level of knowledge regarding alcohol use and its harmful effects among teenagers in pretest. In pretest results revealed that among 60 teenagers 15 (25\%) had Inadequate knowledge, 24 (40\%) had moderate knowledge, 21 (35\%) had adequate knowledge on alcohol use and its harmful effects.

The results of the present study were supported by the earlier study conducted by Arasumani [4] on knowledge and attitude among 60 adolescents towards alcohol use in selected schools in Bangalore. Convenient sampling technique was used. The structured interview schedule was administered. The study results showed $6.7 \%$ had adequate knowledge, $61 \%$ had moderate knowledge, $31.7 \%$ had inadequate knowledge $(r=0.636)$. Regarding demographic data 41 (68\%) of the respondents belongs to Hindu religion, 27 (45\%) were completed educated degree, 29 (48.33\%) were in the family income per month of Rs. $5000-10,000$ and 17 (28.33\%) of respondents were consumed alcohol in the family.

The second objective of the study was to evaluate the effectiveness of structured teaching program by comparing pretest and posttest knowledge scores of teenagers on alcohol use and its harmful effects. In pretest (Table 1), the study findings revealed that among 60 teenagers 15 (25\%) had inadequate knowledge, 24 (40\%) had moderate knowledge, 21 (35\%) had adequate knowledge on alcohol use and its harmful effects, whereas in posttest 8 (13.3\%) had inadequate knowledge, 28 (46.7\%) had moderate knowledge, 24 (40\%) had adequate knowledge on alcohol use and its harmful effects. The pre-test mean score among teenagers were 15.40 , with standard deviation of 4.085 and the post mean score among teenagers 24.08 with, standard deviation of 2.499 and the ' $t$ ' value obtained was 15.486 . Which was statistically significant at $P<0.01$. The results indicate that there was significant difference between pre and post-test knowledge scores after structured teaching program. So in hypothesis $(\mathrm{H} 1)$, "There is a significant difference between the pretest and post test scores of knowledge on alcohol use and its harmful effects among teenagers at Municipal Corporation School" was accepted.

The results of the present study were supported by the earlier study conducted by Jani et al. [5] on "Effectiveness of planned teaching program on knowledge regarding ill effects of alcohol consumption. The sample size was 60 adolescents from selected higher secondary school, Vadodara district, Gujarat, India. Pre experimental design was used. The sampling technique was Non probability convenient sampling. The study results showed in pre-test adolescents were having on average $43.43 \%$ knowledge regarding ill effects of alcohol consumption and means score was 12.43 and standard deviation (SD) was 2.645. In posttest adolescents had $65.33 \%$ knowledge and mean score was 19.60 , standard deviation was 2.599 and t-value was -20.948. Level of significance is $\mathrm{P}=0.05$ level.
Table 1 Frequency and percentage distribution of level of knowledge on alcohol use and its harmful effects among teenagers in pre-test.

\begin{tabular}{|c|c|c|c|c|c|c|}
\hline Variable & \multicolumn{2}{|c|}{$\begin{array}{c}\text { Inadequate } \\
\text { Knowledge } \\
(<50 \%)\end{array}$} & \multicolumn{2}{c|}{$\begin{array}{c}\text { Moderate } \\
\text { Knowledge } \\
(\mathbf{5 1 - 7 5 \% )}\end{array}$} & \multicolumn{2}{|c|}{$\begin{array}{c}\text { Adequate } \\
\text { Knowledge } \\
(\mathbf{7 6 - 1 0 0 \% )}\end{array}$} \\
\hline $\begin{array}{c}\text { Pre-test } \\
\text { (f) }\end{array}$ & (\%) & (f) & $(\%)$ & (f) & $(\%)$ \\
\hline knowledge scores & 15 & 25 & 24 & 40 & 21 & 35 \\
\hline
\end{tabular}

Table 2 Frequency and percentage distribution of level of knowledge on alcohol use and its harmful effects among teenagers in post-test.

\begin{tabular}{|c|c|c|c|c|c|c|}
\hline \multirow[t]{2}{*}{ Variable } & \multicolumn{2}{|c|}{$\begin{array}{c}\text { Inadequate } \\
\text { Knowledge } \\
(<50 \%)\end{array}$} & \multicolumn{2}{|c|}{$\begin{array}{l}\text { Moderate } \\
\text { Knowledge } \\
(51-75 \%)\end{array}$} & \multicolumn{2}{|c|}{$\begin{array}{l}\text { Adequate } \\
\text { Knowledge } \\
(76-100 \%)\end{array}$} \\
\hline & (f) & $(\%)$ & $(f)$ & $(\%)$ & (f) & (\%) \\
\hline $\begin{array}{c}\text { Post-test } \\
\text { knowledge scores }\end{array}$ & 8 & 13.3 & 28 & 46.7 & 24 & 40 \\
\hline
\end{tabular}

The third objective of the study was to find out the association of posttest knowledge scores with selected demographic variables (Table 2). The study findings revealed that age (0.01) at $p<0.05$ level and education of the student (0.01), education of mother (0.02), occupation of father (0.01), pocket money (0.04). In posttest age (0.04), education of the student (0.04), type of family (0.01), education of father (0.02), number of siblings (0.04), occupation of father (0.04), habit of alcohol in family (0.03), pocket money $(0.03)$ at $p<0.05$ level. The results indicate that there was significant association of post-test knowledge scores after structured teaching program. So hypothesis $(\mathrm{H} 2)$ " There is a significant association of post test scores of knowledge on alcohol use and its harmful effects among teenagers at Municipal Corporation School" was accepted.

The results of the present study was supported by the earlier study conducted by Tsering et al. [6] on the knowledge regarding substances use of alcohol and its harmful effects among adolescents high school students in India. The sample size was 416 students in class VIII, IX, X in high schools, selected by multiage random sampling and self-administered anonymous questionnaire was used The study results showed especially in urban areas $46.2 \%$ students and in rural areas $34.6 \%$ students had knowledge about alcohol use and its harmful effects.

\section{Implications}

The implications drawn from the present study are of vital concern to nursing education, health professionals, including nursing service, nursing practice, nursing administration and nursing research.

\section{Conclusion}

The high school children had gained knowledge on Alcohol use and its harmful effects after the structured teaching program in the post test assessment. 


\section{References}

$1 \mathrm{http}: / /$ alcoholthinkagain.com.au/

2 https://drugabuse.com/library/the-effects-of-alcohol-use/

3 https://www.niaaa.nih.gov/alcohol-health/overview-alcoholconsumption/alcohol-facts-and-statistics
4 Arasumani N (2013) Adolescents towards alcoholism in selected colleges in Bangalore. J Sci 3: 59-61.

5 Jani V, Swamy PGN, Ravindra HN, Varghese R (2014) Effectiveness of planned teaching programme on knowledge regarding ill effects of alcohol consumption. IOSR J Nurs Health Care 3: 16-21.

6 Tsering D, Pal R, Dasgupta A (2010) Substance use among adolescent high school students in India: A survey of knowledge, attitude and opinion. J Pharm Bioallied Sci 2: 137-140. 